Abstract 420 Table 2 Cox Regression analysis for all-cause mortality.

\begin{tabular}{|c|c|c|c|c|}
\hline \multicolumn{5}{|c|}{ Cnirariate Cos Regression } \\
\hline & \multirow{2}{*}{ Hazard Ratio } & \multicolumn{2}{|c|}{$95.00 \%$ CIfor Erp(B) } & \multirow{2}{*}{ P-ralue } \\
\hline & & Lotrer & Tpper & \\
\hline Lupos Diagnosis & 1.853 & 1.681 & 2.043 & $<0.001$ \\
\hline \multicolumn{5}{|c|}{ Vultirariate Cos Regression } \\
\hline & \multirow{2}{*}{ Hazard Ratio } & \multicolumn{2}{|c|}{$95.0 \%$ CIfor Егр(B) } & \multirow{2}{*}{ Pralue } \\
\hline & & Lomer & Tpper & \\
\hline Lupus Diagnosis & 1.621 & 1.333 & 1.971 & 0.001 \\
\hline Age & 1.073 & 1.066 & 1.079 & $<0.001$ \\
\hline Year of Incident Hospitalisation & 0.977 & 0.955 & 1.000 & 0.046 \\
\hline Males & 1.427 & 1.171 & 1.739 & 40.001 \\
\hline Length of Stą & 1.012 & 1.006 & 1.018 & 40.001 \\
\hline Cninsured & 1.510 & 1254 & 1.817 & $<0.001$ \\
\hline Kidner Disorder & 1.745 & 1.351 & 2.256 & 40.001 \\
\hline Thrombotic Diseases & 1.759 & 1.124 & 2.752 & 0.013 \\
\hline Cerebralischemia & 2.041 & 1.119 & 3.722 & 0.020 \\
\hline
\end{tabular}

early and aggressive disease control and prevention of complications especially in those with renal involvement.

\section{RELAPSE OF LUPUS NEPHRITIS - RISK FACTORS AND IMPACT OF MYCOPHENOLATE TREATMENT}

DYH Yap*, C Tang, MKM Ma, MM Mok, GC Chan, LP Kwan, TM Chan. Queen Mary Hospital- The University of Hong Kong, Department of Medicine, Hong Kong, Hong Kong S. A.R

\subsection{6/lupus-2017-000215.427}

Background and aims The management of lupus nephritis (LN) has evolved over time. There is limited data on renal flares in the recent era.
Methods We investigated the renal relapse rate in 139 patients with a history of Class III/IV $\pm \mathrm{V}$ diagnosed during the period of Jan 1983 to Dec 2013, and the factors associated with renal flares.

Results 135 episodes of renal relapse occurred over 112.5 \pm 88.4 months, giving a flare rate of 0.108 episode per patient-year. Reduced risk of renal flare was associated with maintenance treatment using mycophenolate (MPA) (OR 0.314, 95\% CI 0.099-0.994, $\mathrm{p}=0.049$ ), complete remission after the prior episode of active LN (OR 0.329, 95\% CI $0.133-0.810, p=0.016$ ), and diagnosis of LN after 1998 (OR $0.305,95 \%$ CI $0.133-0.700, \quad \mathrm{p}=0.005)$ when maintenance therapy with MPA was instituted. Low-dose prednisolone and MPA maintenance immunosuppression was associated with better relapse-free survival (5 year $91 \%$ and 10 year $83 \%$ ) than prednisolone and azathioprine (AZA) (70\% and 
Abstract 424 Table 1 CVE in women with SLE born in Sweden between 1951-1971.

\begin{tabular}{|l|c|c|c|}
\hline & $\begin{array}{c}\text { Non-parous } \\
(n=915)\end{array}$ & $\begin{array}{c}\text { Preterm<34/40 } \\
(n=194)\end{array}$ & $\begin{array}{c}\text { Delivery } \geq 34 / 40 \\
(n=2,119)\end{array}$ \\
\hline CVE, $n$ (\%) & $138(15.1)$ & $30(15.5)$ & $166(7.9)$ \\
\hline Age at 1 st CVE, years (IQR) & $41(33-48)$ & $40.5(31-48)$ & $46(40-51)$ \\
\hline Incidence, per 1,000 person-years (95\% Cl) & $3.44(2.91-4.07)$ & $3.53(2.47-5.05)$ & $1.75(1.50-2.03)$ \\
\hline Adjusted hazard of a CVE, adjHR* (95\% Cl) & $1.42(1.14-1.78)$ & $1.22(1.09-1.37)$ & 1.0 \\
\hline Cl-confidence interval; * adjusted for CV risk factors and SLE-related morbidity. & \\
\hline
\end{tabular}

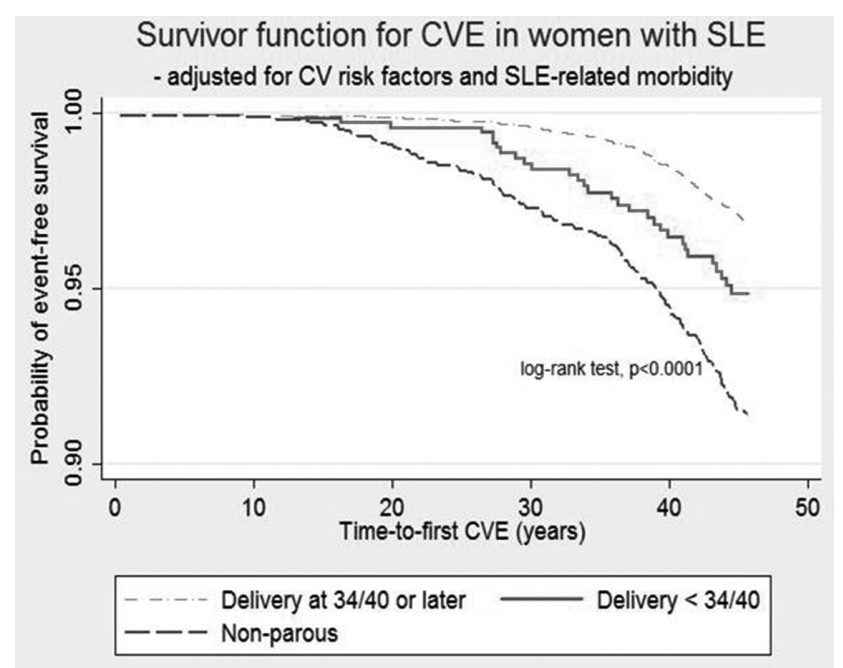

Abstract 424 Figure 1

$52 \%$ respectively, $\mathrm{p}=0.044$ ) (Figure 1 ). LN diagnosed in 1998-2013 was associated with 5 year and 10 year relapsefree survival rates of $93 \%$ and $86 \%$ respectively, compared with $81 \%$ and $66 \%$ respectively $(\mathrm{p}=0.017)$ for patients who presented in 1983-1997 (Figure 2).

Conclusions The risk of renal relapse has decreased in the current era, probably attributed to replacement of AZA with MPA as maintenance treatment.

\section{PRE-EMPTIVE TREATMENT FOR ASYMPTOMATIC SEROLOGICAL REACTIVATION IN LUPUS NEPHRITIS PATIENTS - IMPACT ON CLINICAL FLARE RATE AND RENAL FUNCTION}

DYH Yap*, MK Ma, MM Mok, GC Chan, LP Kwan, TM Chan. Queen Mary Hospital- The University of Hong Kong, Department of Medicine, Hong Kong, Hong Kong S.A.R

10.1136/lupus-2017-000215.428
Background and aims Pre-emptive immunosuppressive treatment for asymptomatic serological activation (ASR) in lupus nephritis (LN) patients remains controversial, and its impact on subsequent flare rate and long-term renal outcome is unclear.

Methods We conducted a retrospective study on all episodes of ASR in 1993-2015 to investigate the relationship between pre-emptive treatment and subsequent clinical flares and renal outcomes.

Results 138 episodes of ASR occurred in 98 patients during the study period. 53 episodes (in 38 patients) were treated with pre-emptive increase in immunosuppression while 85 episodes (in 60 patients) were not, and patients were followed up for $88.8 \pm 77.3$ months and $82.8 \pm 89.7$ months respectively after ASR occurred. Pre-emptive treatment was associated with superior renal relapse-free survival $(100 \%, 95 \%$ and $90 \%$ at 6, 12 and 24 months respectively) compared with no preemptive treatment (93\%, 68\% and 65\% respectively, $\mathrm{p}=0.007)$, while extra-renal relapse-free survival did not differ between the two groups (Figure 1). 5 (9.4\%) of 53 ASR episodes treated pre-emptively developed renal flare at $14.3 \pm 6.7$ months after ASR. Patients who received pre-emptive treatment for ASR and did not develop renal flares showed also better eGFR slope $\left(+0.54 \pm 0.43 \mathrm{ml} / \mathrm{min} / 1.73 \mathrm{~m}^{2} /\right.$ year $)$ compared with the non-pre-emptive groups with or without renal flares $\left(-2.11 \pm 0.50\right.$ and $-1.00 \pm 0.33 \mathrm{ml} / \mathrm{min} / 1.73 \mathrm{~m}^{2} /$ year respectively, $p=0.001$ and 0.012 ) (Figure 2). Pre-emptive treatment was associated with more gastrointestinal adverse events related to increased mycophenolate dose $(p=0.031)$. Infection rate was similar between both groups.

Conclusions Renal flares have a negative impact on renal function and pre-emptive treatment for ASR could reduce renal flare risk and its consequences in LN patients.

\section{ANTIPHOSPHOLIPID ANTIBODY POSITIVITY AND RELATED CLINICAL CHARACTERISTICS IN KOREAN LUPUS PATIENTS}

${ }^{1} \mathrm{~S}$ Nam, ${ }^{1} \mathrm{D} \mathrm{Kim}$ *, ${ }^{1}$ SK Cho, ${ }^{2}$ KE Lee, ${ }^{2} \mathrm{DJ}$ Park, ${ }^{2}$ SS Lee, ${ }^{1}$ YK Sung. ${ }^{1}$ Hanyang University Hospital for Rheumatic Diseases, Rheumatology, Seoul, Republic of Korea; ${ }^{2}$ Chonnam national university medical school and hospital, Rheumatology, Gwangju, Republic of Korea

10.1136/lupus-2017-000215.429 